\title{
HOXB5 Directly Regulates the Expression of IL-6 in MCF7 Breast Cancer Cells
}

\author{
Jie Min Kim, Ji-Yeon Lee and Myoung Hee Kim ${ }^{\dagger}$ \\ Department of Anatomy, Embryology Laboratory, and Brain Korea 21 PLUS Project for Medical Science, \\ Yonsei University College of Medicine, Seoul 03722, Korea
}

\begin{abstract}
HOX genes are transcription factors that play important roles in body patterning and cell fate specification during normal development. In previous study, we found aberrant overexpression of HOXB5 in breast cancer tissues and cell lines, and demonstrated that HOXB5 is important in regulation of cell proliferation, tamoxifen resistance, and invasiveness through the epithelial-mesenchymal transition (EMT). Although the relationship between HOXB5 and phenotypic changes in MCF7 breast cancer cells has been studied, the molecular function of HOXB5 as a transcription factor remains unclear. IL-6 has been reported to be involved in not only inflammation but also cancer progression, which is characterized by the increase of growth speed and invasiveness of tumor cells. In this study, we selected Interleukin-6 (IL-6) as HOXB5 putative downstream target gene and discovered that HOXB5 transcriptionally up-regulated the expression of $I L-6$ in HOXB5 overexpressing MCF7 cells. The upstream region $(\sim 1.2 \mathrm{~kb})$ of $I L-6$ promoter turned out to contain several putative HOX consensus binding sites. Chromatin immunoprecipitation assay confirmed that HOXB5 directly binds to the promoter region of $I L-6$ and positively regulated the expression of $I L-6$. These data all together, indicate that HOXB5 promotes $I L-6$ transcription by actively binding to the putative binding sites located in the upstream region of $I L-6$, which enable to increase its promoter activity in MCF7 breast cancer cells.
\end{abstract}

Key Words: Breast cancer, HOXB5, IL-6, Transcription

현대 의학 기술의 발달에도 불구하고 암은 전 세계적 으로 주된 사망의 요인이다. 2016년도 미국에서 발표한 통계에 따르면 여성에서 유방암이 가장 빈번하게 발생되 고 그 비율은 매년 진단되는 암의 약 $29 \%$ 를 차지한다고 알려져 있다(Siegel et al., 2016). 암은 근본적으로 세포증식 과 세포사멸이 조절되지 않아 발생되는 질병으로 유방암 의 경우 주로 유관과 소엽에서 발병한다. 한곳에서 발병 된 유방암은 주로 림프선, 뼈, 뇌, 간, 그리고 폐와 같은 다른 장기로 전이 된다고 알려져 있다. 최근에는 유방암 을 분류하는 다양한 방법들 중 유방암 세포에서 발현하는 에스트로겐 수용체(estrogen receptor, ER), 프로게스테론 수용체(progesterone receptor, PR), 인간상피증식인자수용 체 2 (Human epidermal growth factor receptor 2, HER-2)의 비율을 토대로 4종류(luminal A, luminal B, HER-2 enriched, triple-negative)의 분자적 아형으로 구분하며, 아형에 따라 유전자들의 발현 양상이나 세포 표현형이 다양할 뿐만 아 니라 치료 방법과 예후에도 서로 다른 차이를 보인다고 알려져 있다(Allison, 2012).

$H O X$ 유전자는 발생 과정 동안 일어나는 여러 종류의 세포 내 반응을 조절하는 전사 조절 인자(transcription factor, $\mathrm{TF}$ )로 알려져 있으며, 특히 배 발생 과정 중 시공간 특이 적으로 발현하여 배아의 전후축 형태 형성 과정에 있어

*Received: July 2, 2017 / Revised: August 23, 2017 / Accepted: August 24, 2017

${ }^{\dagger}$ Corresponding author: Myoung Hee Kim. Department of Anatomy, Yonsei University of College of Medicine, Seoul 03722, Korea. Tel: +82-2-2228-1647, Fax:+82-2-365-0700, e-mail: mhkim1@yuhs.ac

(C) The Korean Society for Biomedical Laboratory Sciences. All rights reserved.

(c) This is an Open Access article distributed under the terms of the Creative Commons Attribution Non-Commercial License (http://creativecommons.org/licenses/by-nc/3.0/) which permits unrestricted non-commercial use, distribution, and reproduction in any medium, provided the original work is properly cited. 
서 매우 중요한 역할을 담당한다고 알려져 있다(Gehring and Hiromi, 1986; Wang et al., 2009). 성인에서도 HOX 유 전자의 발현이 규칙적으로 조절되고, 비정상적인 $\mathrm{HOX}$ 유 전자의 발현이 폐암(Abe et al., 2006), 자궁경부암(Li et al., 2002), 신장암(Cillo et al., 1992) 등 다양한 악성종양 조직 에서 보고되었다. 유방암의 경우 조직과 세포에서 $\mathrm{HOX}$ 유전자 전체의 발현 양상을 비교해 보았을 때, 다양한 $H O X$ 유전자들의 발현이 악성과 비악성에서 차이가 있음 이 보고되었다(Hur et al., 2014). 특히 혈관(Fessner et al., 2014), 장(Zhu et al., 2011) 그리고 신경능(Kam et al., 2014) 발달에 있어서 중요한 역할을 한다고 알려진 HOXB5는 위(Hong et al., 2015), 폐(Zhang et al., 2017), 식도(Sun et al., 2016) 등에서 종양의 진행과 전이에서의 중요성이 알려져 있으며, 유방암 조직에서 그 발현량이 정상 조직에 비하 여 증가되어 있다. 특히 증가된 $\mathrm{HOXB5}$ 는 세포증식, 암 의 침습성, 상피간엽이행(epithelial-mesenchymal transition, EMT), Tamoxifen 저항성을 나타내는데 기여한다는 것이 알려져 있다(Lee et al., 2015).

암세포가 살아남고 증식하기 위해서는 주변 환경과 상 호작용 하는 것이 필수적이며 특히 면역계와의 관계는 매 우 중요하다. 인터루킨-6(Interleukin-6, IL-6)는 T-세포, 대식 세포와 같은 면역세포로부터 분비되는 전염증성 사이토 카인(pro-inflammatory cytokine)으로 암 진행 뿐만 아니라 암 발생에도 기여하며(Mantovani et al., 2008; Coussens et al., 2013), 과발현 되었을 경우 환자 예후에 안 좋은 영향을 끼친다고 알려져 있다(Lin et al., 2015). 특히 유방암의 진행 에 있어서 IL-6는 E-cadherin 발현을 억제함으로써 EMT를 유도한다고 알려져 있으며(Sullivan et al., 2009), 유방암 치 료제로 널리 사용되는 Tamoxifen에 대한 내성에 있어서 도 증가된 $\mathrm{IL}-6$ 의 발현이 관련되어 있다고 보고되어 있다 (Shah et al., 2013).

본 연구에서는 HOXB5가 IL-6의 발현을 조절하여 vascular remodeling에 관여한다는 보고(Fessner et al., 2014)에 따라 유방암에서도 HOXB5가 IL-6의 발현을 조절하는 지 알아보고자 하였다. 먼저 3 개의 HOXB5 과발현 유방 암 세포주(HOXB5 overexpressing MCF7)와 2개의 대조군 MCF7 세포주(Lee et al., 2015)를 이용하여 IL-6 유전자의 발현 양을 분석하였다. RT-PCR 방법으로 분석해 본 결과 (Fig. 1), HOXB5를 과발현하는 MCF7 세포는 대조군 세포 보다 $I L-6$ 의 발현이 현저히 증가해 있음을 알 수 있었다: IL-6 forward primer; 5'- GAA CCT TCC AAA GAT GGC TG-3', IL-6 reverse primer; 5'- CAG GGG TGG TTA TTG

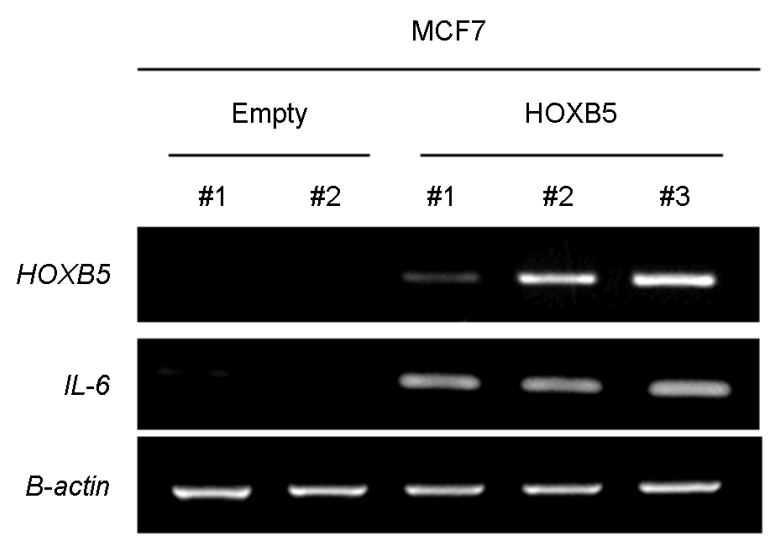

Fig. 1. Expression pattern of HOXB5 and IL-6 in HOXB5 overexpressing (HOXB5) and control (Empty) MCF7 breast cancer cells. Two control (Empty, \#1 and \#2) and three HOXB5 overexpressing cell lines (HOXB5, \#1, \#2, and \#3) were used for RT-PCR analysis. Beta-actin gene was included as an internal control.

CAT CT-3' (product size: $230 \mathrm{bps),} \mathrm{HOXB5와} \beta$-actin internal control primer는 이전 논문(Lee et al., 2015) 참고.

$\mathrm{HOX}$ 는 호메오 도메인 단백질(Homeodomain protein)로 서 Hox consensus binding sequence (TAAT, ATTA, TTAT, ATAA, TTAC)를 인식함으로써 유전자의 발현을 조절한 다고 알려져 있다(Spitz and Furlong, 2012). 본 연구에서는 $\mathrm{HOXB} 5$ 가 $I L-6$ 의 발현을 직접 조절하는지 알아보기 위하 여 먼저 IL-6 유전자의 upstream 프로모터 지역(-1,200 bp $\sim+50$ )에서 Hox consensus binding sites를 분석하였다. 그 다음 서로 다른 Hox consensus binding sites를 포함하고 있 는 upstream 프로모터 부위를 pGL3-basic plasmid에 클로 닝 하여(IL-6_F1 F: 5'- GGG TAC GCT CTG ACC GCT GAC -3', product size: 1,102 bps., IL-6_F2 F: 5'- GGG TAC GCG TGG GTC GAG AAA -3', product size: 454 bps., IL-6_F1/F2 R: 5'- TCC CCG GTT CGA CTG GCC GTT T-3') pGL3IL-6_F1/F2 plasmids를 제작한 다음, 이 두 플라스미드의 프로모터 활성을 Dual-luciferase reporter assay (Promega, Madison, USA)를 통해 수행하였다. MCF7 cells이 존재하는 24 well plate에 루시퍼레이즈 활성을 갖는 pGL3-IL-6_F1/ $\mathrm{F} 2$ 와 HOXB5를 발현하는 pcDNA3-HA-HOXB5 plasmid 혹은 control인 pcDNA3-HA plasmid (empty)를 Attractene transfection reagent (Qiagen, Hilden, Germany)를 사용하여 같이 트랜스펙션 하였다. Internal control로서 pRL-TK Renilla uciferase vector (Promega)도 같이 넣어주었다. 트랜스펙션 시키고 48시간 후에 Dual-luciferase kit (Promega)와 Sub- 
scription fluorescence detector (GloMAx 20/20 IuMINoMeTeR, Promega)를 이용하여 cell lysates에서 발생하는 루시퍼레이 즈 활성을 측정하였다. 각각 실험에서 발생되는 루시퍼레 이즈 활성은 internal control인 Renilla luciferase 활성을 이
용하여 Renilla luciferase units (RLU)으로 정량하였다. Cotransfection 시키고 luciferase activity와 함께 HOXB5가 과 발현되고 있음을 RT-PCR로 확인하였고(Fig. 2A lower-left panel), HOXB5가 존재하는 경우에 pGL3-IL-6_F1/F2 모

(A)

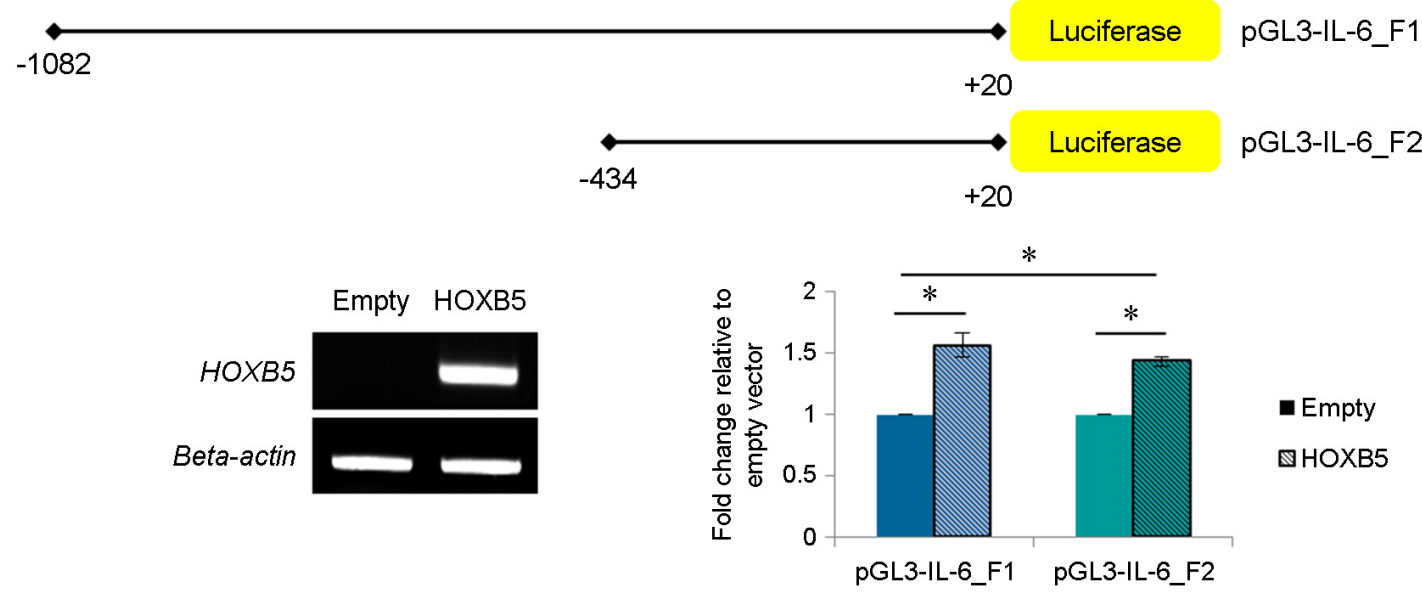

B
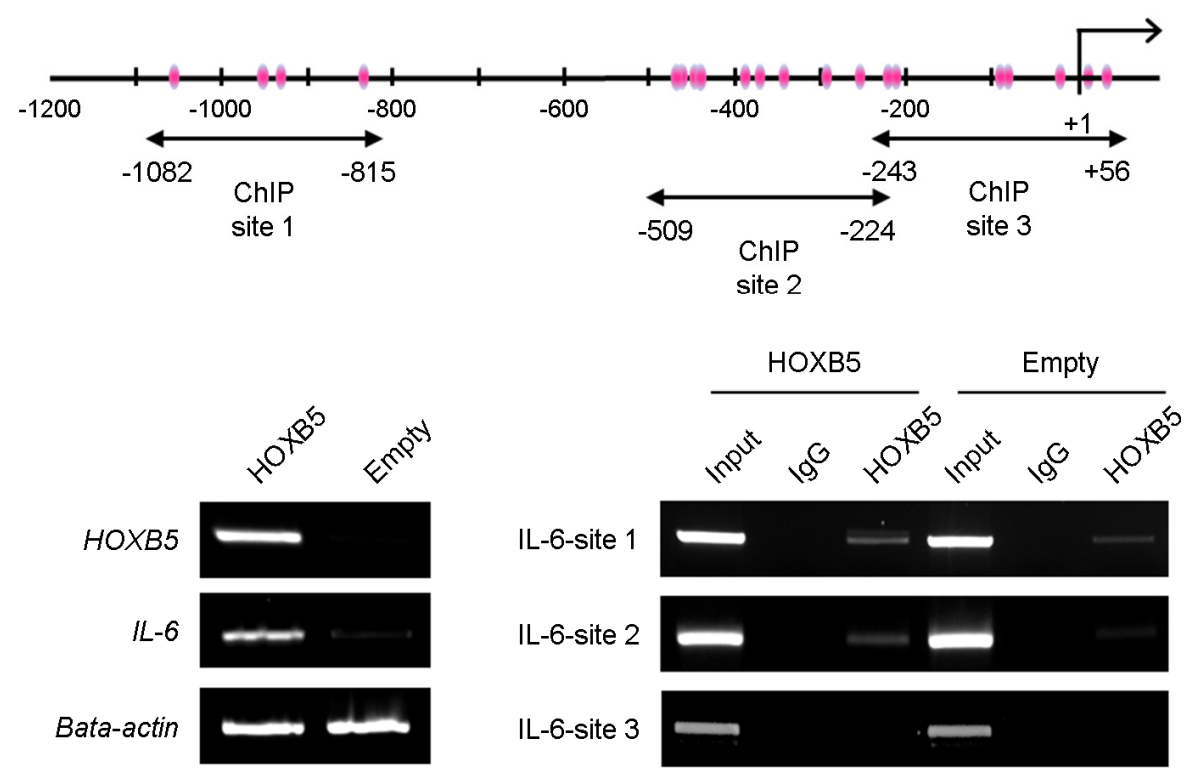

Fig. 2. Effect of HOXB5 on $I L-6$ expression. (A) pGL3-IL-6 F1/F2 plasmids containing different length of the upstream regulatory regions of IL-6. MCF7 cells were plated at a density of $5.5 \times 10^{4}$ cells per well in a 24-well plate for transfection. pGL3-IL-6-promoter constructs (pGL3-IL-6 F1 and F2) were co-transfected with effector plasmids, pcDNA3-HA (Empty) or pcDNA3-HA-HOXB5 (HOXB5). Transfected cells were harvested after $48 \mathrm{~h}$ of transfection. Luciferase activity was measured and normalized to that of Renilla luciferase used as an internal control. Data are shown with the mean \pm SEM of triplicates. *, $P<0.001$, by Student's $t$-test. (B) Schematic depiction of the $\sim 1.2 \mathrm{~kb}$ upstream regulatory region of IL-6 (Chr7:22725942+22727241 in UCSC genome browser). Putative Hox core consensus binding elements (TAAT/ ATTA/TTAT/ATAA/TTAC) are marked with pink ovals. Black arrow shows ChIP-site. Expression level of HOXB5, IL-6 was analyzed by RT-PCR in control (Empty) and HOXB5 overexpressing (HOXB5) cells (lower left panel). ChIP-PCR analysis in empty and HOXB5 overexpressing MCF7 stable cell lines (lower right panel). Chromatins were precipitated in the presence of anti-HOXB5 antibody (lanes 3 and 6) or anti-mouse IgG (lanes 2 and 5), and then the precipitated chromatin was subjected to PCR by using ChIP-specific primers. Input (prior to immunoprecipitation) was used as an internal control (lanes 1 and 4). 
두 프로모터 활성이 증가됨을 확인할 수 있었다(Fig. 2A lower-right panel). 또, IL-6_F1이 IL-6_F2에 비하여 HOXB5 에 대한 responsiveness가 조금 더 높았으며, 이것이 확률 적으로 유의함을 확인하였다. 이상의 결과로부터 HOXB5 가 IL-6 유전자의 promoter 활성을 양성적으로 조절함으 로써 $I L-6$ 의 발현을 증가시킨다는 것을 알 수 있었다.

그 다음 이 양성적 조절이 HOXB5의 직접적인 결합에 의한 것인지 알아보기 위하여, 염색질 면역침전 분석 (Chromatin immuno-precipitation assay, ChIP)을 수행하였다. Empty MCF7 cells와 HOXB5 과발현 MCF7 cells를 배양 한 후 필요한 수에 맞게 세포를 수확하였다. 세포를 $1 \%$ formaldehyde로 15 분간 실온에서 고정시키고, glycine을 최 종 농도 $0.125 \mathrm{M}$ 이 되도록 넣어 고정을 멈춰주었다. 차가 운 PBS로 wash 후, Protease inhibitor (Roche)가 들어있는 ChIP lysis buffer (1\% SDS, 10 mM EDTA, 50 mM Tris-Cl [pH $8])$ 를 넣고 ice에서 10 분간 보관한 다음 sonicator를 이용 하여 chromatin DNA 단편의 크기가 $500 \sim 100 \mathrm{bps}$ 되도록 절단시켰다. Sonicated sample을 $8,000 \mathrm{xg}$ 로 $4^{\circ} \mathrm{C}$ 에서 1 분간 원심분리한 후 상층액 중 $50 \mu \mathrm{L}$ 를 사용하여 농도 측정 과 input으로 사용하고 나머지 상층액을 따로 분리하여 protease inhibitor와 RIPA buffer $(0.1 \%$ SDS, $0.5 \%$ sodium deoxycholate, 1\% NP-40, 2 mM EDTA [pH 8.0], $150 \mathrm{mM}$ $\mathrm{NaCl}, 50 \mathrm{mM}$ Tris-Cl [pH 8.0]), Protein A/G PLUS-Agarose (Snata Cruz Biotechnology, Inc.) 그리고 salmon sperm DNA $(10 \mu \mathrm{g} / \mathrm{mL})$ 를 첨가한 후 $4^{\circ} \mathrm{C}$ 에서 1 시간 동안 pre-clear 시 켰다. $2,000 \mathrm{rpm}$ 으로 5 분간 $4{ }^{\circ} \mathrm{C}$ 에서 원심분리 후, 동량의 상층액을 각각 새로운 tube에 옮기고, $\mathrm{IgG}$ control (Santa Cruz, CA, USA., Cat. No. sc-2025)과 anti-HOXB5 antibody (Santa Cruz, Cat. No. sc-81099)를 각각 첨가하였다. 여기에 다시 Protein A/G PLUS-Agarose (Snata Cruz)를 첨가한 후 $4{ }^{\circ} \mathrm{C}$ 에서 18 시간 이상 면역침강반응을 시켰다. 항체가 붙 어있는 complex를 원심분리한 다음 wash buffer $(0.1 \% \mathrm{SDS}$, 1\% triton-x-100, 2 mM EDTA, 20 mM Tris-Cl [pH 8.0], 150 mM $\mathrm{NaCl})$ 로 3 회, final wash buffer $(0.1 \% \mathrm{SDS}, 1 \%$ triton-x- 100 , $2 \mathrm{mM}$ EDTA, $20 \mathrm{mM}$ Tris-Cl [pH 8.0], $500 \mathrm{mM} \mathrm{NaCl}$ )로 1회 wash하고, elution buffer $(1 \% \mathrm{SDS}, 100 \mathrm{mM} \mathrm{NaHCO}$ )를 사용 하여 chromatin을 추출하였다. 추출된 chromatin을 reverse cross-links하기 위하여 RNase $\mathrm{A}$ 를 넣어 $65^{\circ} \mathrm{C}$ 에서 4시간 반 응시킨 다음 PCR purification kit (COSMO Genetech Co., $\mathrm{Ltd}$, Seoul, Korea)를 이용하여 추출한 DNA를 정제시켰다. $\mathrm{HOXB} 5$ 가 직접 $\mathrm{DNA}$ 에 붙는지 확인하기 위해 Hox consensus binding site의 분포를 고려하여(Fig. 2B, upper panel)
ChIP-PCR primer를 디자인 하고(IL-6 site 1 F: 5'- GCT TCT GAA CCA GCT TGA CC-3', IL-6 site 1 R: 5'- GTC TCC TGG AGC CCT GAA AT-3', product size: 268 bps., IL-6 site 2 F: 5'AGG GAG AGC CAG AAC AC-3', IL-6 site 2 R: 5'- CAG CAC TTT GGC ATG TCT TG-3', product size: 286 bps., IL-6 site 3 F: 5'- CAA GAC ATG CCA AAG TG-3', IL-6 site 3 R: 5'GCC TCA GAC ATC TCC AGT CC-3', product size: 299 bps.), 정제한 $\mathrm{DNA}$ 를 template로 ChIP-PCR을 수행하였다. 먼저 $\mathrm{HOXB} 5$ 과발현 MCF7 cells에서 IL-6 mRNA의 발현이 증 가됨을 RT-PCR로 확인한 후, 각각의 primer로 ChIP-PCR 을 수행한 결과 $\mathrm{ChIP}$ site 1과 $\mathrm{ChIP}$ site 2에 HOXB5가 붙 는다는 것을 알 수 있었다(Fig. 2B). 이상의 결과로부터, HOXB5 과발현 세포주에서 나타나는 $I L-6$ 의 발현 증가는 $\mathrm{HOXB} 5$ 가 직접적으로 $I L-6$ upstream promoter 서열과 결합 함으로써 야기된다는 것과 특히 site 1 , site 2 지역에 존재 하는 Hox consensus binding site가 중요한 역할을 할 것이 라는 것을 유추할 수 있었다.

이상의 결과는 악성 유방암에서 증가된 HOXB5가 IL-6 유전자의 upstream 프로모터 지역에 존재하는 Hox consensus binding sites에 직접 붙음으로써 $I L-6$ 의 프로모터 활 성을 증가시켜 $I L-6$ 유전자의 발현을 양성적으로 조절한 다는 것을 의미한다. 최근 Shah 등(2013)은 유방암에서 HOXB13이 ER-alpha를 억제하고 $I L-6$ 발현을 증가시킴으 로서 tamoxifen 저항성과 invasiveness를 유도하였다고 보 고하였다. 본 실험실에서도 선행연구에서 HOXB5가 과발 현하면 유방암의 증식과 invasiveness가 유도된다는 것을 보고한 바 있으며(Lee et al., 2015), 이는 아마도 전사인자 인 $\mathrm{HOXB} 5$ 가 $I L-6$ 의 조절서열에 직접 결합하여 $I L-6$ 과발 현이 유도되어 나타난 결과로 유추되어진다. 최근 분자적 진단 기술과 표적치료 기술이 나날이 발달함에 따라 유방 암의 개괄적인 양상 보다는 환자 개개인 별 맞춤식 항암 치료법(personalized therapy)이 연구, 적용되고 있다. 따라 서, HOXB5의 target 유전자인 $I L-6$ 의 발현 조절 기전을 분 자 수준에서 밝힌 것은 HOXB5 과발현 유방암 환자군의 치료법을 개발함에 있어 좋은 응용 타겟 유전자가 될 수 있을 것으로 유추된다.

\section{ACKNOWLEDGEMENTS}

김지민 학생은 BK21 PLUS 사업(연세대학교 의과대학 의과학사업단)으로 지원을 받았으며, 본 연구는 한국연구 재단 중견연구사업(2016R1A2B2011821)으로 수행되었습 니다. 


\section{CONFLICT OF INTEREST}

The authors have no conflicts of interest to disclose.

\section{REFERENCES}

Abe M, Hamada J, Takahashi O, Takahashi Y, Tada M, Miyamoto M, Morikawa T, Kondo S, Moriuchi T. Disordered expression of HOX genes in human non-small cell lung cancer. Oncology Reports. 2006. 15: 797-802.

Allison KH. Molecular pathology of breast cancer: what a pathologist needs to know. Journal Of Clinical Pathology. 2012. 138: $770-780$.

Cillo C, Barba P, Freschi G, Bucciarelli G, Magli MC, Boncinelli E. HOX gene expression in normal and neoplastic human kidney. International Journal of Cancer. 1992. 51: 892-897.

Coussens LM, Zitvogel L, Palucka AK. Neutralizing tumorpromoting chronic inflammation: a magic bullet? Science. 2013. 339: 286-291.

Fessner A, Esser JS, Bluhm F, Grundmann S, Zhou Q, Patterson C, Bode C, Moser M. The transcription factor HoxB5 stimulates vascular remodelling in a cytokine-dependent manner. Cardiovascular Research. 2014. 101: 247-255.

Gehring WJ, Hiromi Y. Homeotic genes and the homeobox. Annual Review of Genetics. 1986. 20: 147-173.

Hong CS, Jeong O, Piao Z, Guo C, Jung MR, Choi C, Park YK. HOXB5 induces invasion and migration through direct transcriptional up-regulation of beta-catenin in human gastric carcinoma. Biochemical Journal. 2015. 472: 393-403.

Hur H, Lee JY, Yun HJ, Park BW, Kim MH. Analysis of HOX gene expression patterns in human breast cancer. Molecular Biotechnology. 2014. 56: 64-71.

Kam MK, Cheung MC, Zhu JJ, Cheng WW, Sat EW, Tam PK, Lui VC. Perturbation of Hoxb5 signaling in vagal and trunk neural crest cells causes apoptosis and neurocristopathies in mice. Cell Death \& Differentiation. 2014. 21: 278-289.

Lee JY, Hur H, Yun HJ, Kim Y, Yang S, Kim SI, Kim MH. HOXB5 promotes the proliferation and invasion of breast cancer cells. International Journal of Biological Sciences. 2015. 11: 701-711.

Li H, Huang CJ, Choo KB. Expression of homeobox genes in cervical cancer. Gynecologic Oncology. 2002. 84: 216-221.

Lin S, Gan Z, Han K, Yao Y, Min D. Interleukin-6 as a prognostic marker for breast cancer: a meta-analysis. Tumori Journal. 2015. 101: 535-541.

Mantovani A, Allavena P, Sica A, Balkwill F. Cancer-related inflammation. Nature. 2008. 454: 436-444.

Shah N, Jin K, Cruz LA, Park S, Sadik H, Cho S, Goswami CP, Nakshatri H, Gupta R, Chang HY, Zhang Z, Cimino-Mathews A, Cope L, Umbricht C, Sukumar S. HOXB13 mediates tamoxifen resistance and invasiveness in human breast cancer by suppressing ERalpha and inducing IL-6 expression. Cancer Research. 2013. 73: 5449-5458.

Siegel RL, Miller KD, Jemal A. Cancer statistics, 2016. CA: A Cancer Journal for Clinicians. 2016. 66: 7-30.

Spitz F, Furlong EE. Transcription factors: from enhancer binding to developmental control. Nature Reviews Genetics. 2012. 13 613-626.

Sullivan NJ, Sasser AK, Axel AE, Vesuna F, Raman V, Ramirez N, Oberyszyn TM, Hall BM. Interleukin-6 induces an epithelialmesenchymal transition phenotype in human breast cancer cells. Oncogene. 2009. 28: 2940-2947.

Sun KY, Peng T, Chen Z, Huang J, Zhou XH. MicroRNA-1275 suppresses cell growth, and retards G1/S transition in human nasopharyngeal carcinoma by down-regulation of HOXB5. Journal of Cell Communication and Signaling. 2016. 10: 305 $-314$

Wang KC, Helms JA, Chang HY. Regeneration, repair and remembering identity: the three Rs of Hox gene expression. Trends in Cell Biology. 2009. 19: 268-275.

Zhang B, Li N, Zhang H. Knockdown of Homeobox B5 (HOXB5) inhibits cell proliferation, migration, and invasion in non-small cell lung cancer cells through inactivation of the Wnt/betacatenin pathway. Oncology Research. 2017. 7: 81527-81540.

Zhu J, Garcia-Barcelo MM, Tam PK, Lui VC. HOXB5 cooperates with NKX2-1 in the transcription of human RET. PLoS One. 2011. 6: e20815.

https://doi.org/10.15616/BSL.2017.23.3.272

Cite this article as: $\mathrm{Kim} \mathrm{JM}$, Lee JY, Kim MH. HOXB5 Directly Regulates the Expression of IL-6 in MCF7 Breast Cancer Cells. Biomedical Science Letters. 2017. 23: 272-276. 